Original Article

\title{
PUBLIC PRIVATE PARTNERSHIP AS A TREATM ENT STRATEGY FOR TUBERCULOSIS UNDER DOTS IN COASTAL SOUTH INDIA
}

\author{
Rama Prakasha S. ', Suresh G. ${ }^{2}$, Ivor Peter D'sa ${ }^{3}$, Shobha Shetty S. ${ }^{4}$, \\ Ganesh Kumar $S^{5}{ }^{5} \&$ Manamohan Shetty ${ }^{6}$ \\ ${ }^{1}$ Asst.Professor, ${ }^{2}$ Asst. Professor, ${ }^{3}$ Professor, ${ }^{4}$ Associate Professor, Department of General Medicine, K. S. Hegde Medical \\ Academy, Nitte University, M angalore - 575 018, Karnataka, India. ${ }^{5}$ Asst. Professor, Dept. of Preventive and Social \\ Medicine, JIPM ER, Puducherry, ${ }^{6}$ DOTS Center, K.S. Hegde Medical Academy, M angalore - 575 018, Karnataka, India. \\ Correspondence : \\ Rama Prakasha S. \\ E-mail : dr_prakashbhat@yahoo.co.in
}

\begin{abstract}
:
Limited information is available regarding the functioning of DOTS (Directly Observed Treatment Short course) center for tuberculosis treatment under public private partnership with a medical college hospital. The present study was done to assess the various parameters related to the effectiveness of follow up treatment and its outcome in a DOTScenter attached to a medical college hospital in coastal South India.

Reports of patients with tuberculosis diagnosed and treated under Revised National Tuberculosis Control Programme at KS Hegde M edical College hospital DOTS center under Mangalore TB unit were reviewed retrospectively for the period from July 2004 to June 2011. Data was described in proportion and chi squaretest was applied to assess the association of cases with age group and sex. Among 60 patients serially registered under DOTS, 41 (68.33\%) cases were females and 19 (31.67\%) cases were males. Maximum number of cases belonged to $15-29$ years age group $(20,33.3 \%)$ and the difference observed between the categories of TB and age group was found to be significant $(\mathrm{P} \triangleleft 0.001)$. Overall $23(38.33 \%), 12(20 \%)$ and $25(41.67 \%)$ cases received Cat-I, Cat-II and Cat-III treatment respectively. Success rate for new smear positive cases was $92.85 \%(13 / 14)$ and for Re-treatment smear positive cases was $88.89 \%$ (8/9). Sputum conversion rate among new smear positive cases $(n=14)$ at 2 months and 3 months was $85.71 \%$ and $92.86 \%$ respectively. Sputum conversion rate for Re-treatment cases $(n=9)$ at 2 months and 3 months was $55.56 \%$ and $88.89 \%$ respectively. RNTCP is running successfully in this DOTS center with very low treatment failure rate and better outcome indicators, highlighting the importance of public private partnership of poorly functioning DOTS centers with medical colleges.
\end{abstract}

Keywords : Public Private Partnership, DOTSstrategy, Tuberculosis

\section{Introduction :}

The Government of India evolved a revised strategy and launched the Revised National Tuberculosis Control Programme (RNTCP) based on DOTS strategy in the country in 1997. India is the highest TB burden country accounting for one fifth (21\%) of the global incidence. ${ }^{[1]}$ In India, the annual new smear-positive case detection rate was $66 \%$ in 2005 and treatment success rate was $86 \%$ in $2004{ }^{[2]}$ and $87 \%$ in $2010 .{ }^{[1]}$ The goal of RNTCP includes detection of at least $70 \%$ of new sputum-positive cases and achieving a cure rate of at least $85 \%$ among such cases in the population. ${ }^{[3]}$ TB prevalence and TB mortality in the country has reduced as per the WHO global TB report, 2009 and 2010. As per the vision and targets of RNTCP (2012-17) the goal is successful treatment of at least $90 \%$ of all new TB patients, and at least $85 \%$ of all previously treated TB patients. ${ }^{[1]}$ In this regard there is a need to look for the effectiveness of functioning of DOTS center under public private partnership of medical college hospitals so that its applicability to a larger scale can be elucidated. Very few studies have been conducted in India in this regard. With this background, the present study aims to assess the implementation and outcome of DOTS center attached to a medical college hospital in coastal South India.

\section{Materials and methods:}

The study included retrospective analysis of hospital records and treatment cards. It was done at the DOTS center at Deralakatte, located on the outskirts of Mangalore city of Karnataka, India. Patients with the diagnosis of tuberculosis who preferred to take the medicines from this DOTS center from 2004 July to 2011 June were included in the study. This center under 
Mangalore TB unit is attached to K. S. Hegde Medical College Hospital in this rural area. The DOTS programme was started and implemented across Dakshina Kannada district, Karnataka over a period of time (January 2003December 2004) covering the entire population of 18,97 , 730 (2001 census). DOTS was started in this center attached to K. S. Hegde Hospital in the month of July, 2004.

The RNTCP adopted the WHO recommendations and guidelines for treatment of TB patients and for monitoring and evaluation of programme activities. Briefly, patients with signs and symptoms suggestive of TB were investigated and put on treatment. Patients with at least two sputum smears positive for Acid-Fast Bacillus, or one sputum-positive smear with either positive sputum culture or suggestive chest X-ray for TB were considered smear positive. Since 1st April, 2009, the number of specimen required for diagnosis of smear-positive pulmonary TB is two, with one of them being a morning sputum specimen. One specimen positive out of the two is enough to declare a patient as smear-positive TB. Those with three negative smears were requested to undergo chest $\mathrm{X}$-ray and treated with the antibiotics and then re-evaluated for diagnosis of smear-negative pulmonary TB. Diagnosis of extra pulmonary TB (EPTB) was made clinically and by the laboratory investigations. After diagnosis of TB, patients were referred to the DOTS center where they were registered for treatment. New smear-positive patients in the DOTS clinic received a six-month short-course therapy including thrice weekly supervised dose of rifampicin (R), isoniazid (I), pyrazinamide (Z), ethambutol (E) for two months, followed by self-administered RH for four months $\left(2 \mathrm{H}_{3} \mathrm{R}_{3} \mathrm{Z}_{3} \mathrm{E}_{3} / 4 \mathrm{H}_{3} \mathrm{R}_{3}\right)$. New smear-positive patients were monitored by smear examination at the end of the second and fourth month, and at the end of treatment. New smear-negative and EPTB cases received thrice weekly $\mathrm{RHZ}$ in the first two months followed by $\mathrm{RH}$ for four months $\left(2 \mathrm{R}_{3} \mathrm{H}_{3} \mathrm{Z}_{3} / 4 \mathrm{R}_{3} \mathrm{H}_{3}\right)$ and were monitored by regularity of attendance and clinical improvement. All forms of retreatment patients received supervised thrice weekly dose of streptomycin, rifampicin, isoniazid, pyrazinamide, ethambutol for two months and one-month HRZE followed by RHE for five months $\left(2 \mathrm{R}_{3} \mathrm{H}_{3} \mathrm{Z}_{3} \mathrm{E}_{3} \mathrm{~S}_{3} / 1 \mathrm{R}_{3} \mathrm{H}_{3} \mathrm{Z}_{3} \mathrm{E}_{3} / 5 \mathrm{R}_{3} \mathrm{H}_{3} \mathrm{E}_{3}\right)$.
Data was entered in SPSS version 11 and depicted in tables using proportion. Chi square test was done to look for the association between age and sex with different categories of Tuberculosis.

\section{Results:}

Among 60 patients serially registered under DOTS for treatment, $41(68.33 \%)$ cases were females and 19 (31.67\%) cases were males. 14 cases (23.33\%) were new smear positive cases and 9 (15\%) were Re treatment smear positive cases ( 5 Treatment failure and 4 Relapse). 19 cases (31.67\%) were treated as smear negative cases and 3 cases were treated as smear negative Re treatment Others. 15 cases had EPTB. Overall 23(38.33\%), 12(20\%) and 25(41.67\%) cases received Cat-I, Cat-II and Cat-III treatment respectively. ${ }^{[\text {Table-1] }} \mathrm{M}$ aximum number of cases belonged to $15-29$ years age group ( $20,33.3 \%$ ). 8 females compared to 4 males received Cat-II treatment. 16 children below 14 years age group were treated for smear negative pulmonary TB with symptoms of cough and fever and positive M antoux test. Among 15 EPTB cases; 8 had pleural effusion, 6 had lymph node TB and 1 had abdominal TB.

Sputum conversion rate among new smear positive cases $(n=14)$ at 2 months and 3 months was $85.71 \%$ and $92.86 \%$ respectively. Sputum conversion rate for Re-treatment cases $(n=9)$ at 2 months and 3 months was $55.56 \%$ and 88.89\% respectively. ${ }^{\left[{ }^{[a b l e-2]}\right.}$ Treatment success rate for new smear positive cases was $92.85 \%$ (13/14) and for Retreatment smear positive cases was $88.89 \%(8 / 9)$. Treatment success rate for category III was $100 \%$. Overall failure rate was $3.33 \%(2 / 60)$ and there were no defaulters or transferred out cases.

\section{Discussion :}

In the present study, maximum number of cases belonged to $15-29$ years age group $(20,33.3 \%)$ followed by $1-14$ years age group $(16,26.67 \%)$. Females outnumbered males ( $68.33 \%$ vs. $31.67 \%)$. Since this is a hospital based study, it may not represent the estimation of burden prevalent in the community. Treatment success rate among NSP cases and Re-treatment smear positive cases was $92.86 \%$ and $88.89 \%$ respectively. Only one patient on 
category I was declared as treatment failure and was later declared cured at the end of catyegory II treatment. 8 among 9 Re-treatment smear positive cases under category II were declared cured at the end of the treatment. The study showed that success rates in terms of cure and treatment completion rates were much higher compared to the national average of $87.0 \%$ and $71 \%$ among the NSP and re-treatment smear positive cases respectively. ${ }^{[4]}$ This is likely to be due to the constant follow up with regular investigations and treatment of complications if any and counseling by the treating doctors. These rates were much less in the studies reported by various authors earlier. ${ }^{[5,6,7]}$ Also, the cure rate among NSP cases in entire Dakshina Kannada district in 2003, 2004 and 2005 was $85 \%, 81 \%$ and $79 \%$ serially. ${ }^{[8]}$

There were no defaulters in the present study. During 2005 the default rate was $10.4 \%$ in the entire Dakshina Kannada district. ${ }^{[8]}$ The average rate of default for India was high at $6 \%$ among NSP and $14 \%$ among re-treatment cases. ${ }^{[4]}$ The default rate observed in the present study was quite low compared to the studies reported by other authors as well. $[5,6,9]$

The sputum conversion rate among NSP cases at 3 months was $92.86 \%$. Similar high rates have also been recorded by other studies also. ${ }^{[9,10]}$ Among the re-treatment cases, the overall conversion rate was $88.89 \%$. This rate was much higher than the reportsfrom other studies. ${ }^{[5,9]}$

Table-1: Distribution of subjects according to age and $\operatorname{sex}(\mathrm{N}=60)$

\begin{tabular}{|c|c|c|c|l|}
\hline $\begin{array}{c}\text { Age Group } \\
\text { (Yrs.) }\end{array}$ & $\begin{array}{c}\text { Category-I } \\
\text { No (\%). }\end{array}$ & $\begin{array}{c}\text { Category-II } \\
\text { No. (\%) }\end{array}$ & $\begin{array}{c}\text { Category-III } \\
\text { No. (\%) }\end{array}$ & \\
\hline Age group & & & & 4 \\
$1-14$ & 0 & 0 & $16(100)$ & $44,<0.001$ \\
$15-29$ & $12(60)$ & $4(20)$ & $4(20)$ & \\
$30-44$ & $1(11.11)$ & $3(33.33)$ & $5(55.56)$ & \\
$45-59$ & $9(75)$ & $3(25)$ & 0 & \\
$>60$ & $1(33.33)$ & $2(66.67)$ & 0 & \\
\hline Sex & & & & $0.328 \mathrm{E}-01$, \\
Male & $7(11.67)$ & $4(6.67)$ & $8(13.33)$ & 0.984 \\
Female & $16(26.67)$ & $8(13.33)$ & $17(28.33)$ & \\
\hline Total & $23(38.33 \%)^{*}$ & $12(20 \%)^{*}$ & $25(41.67 \%)^{\circ}$ & \\
\hline
\end{tabular}

New smear positive-14, smear negative-1, Extra-pulmonary-8

\& Relapse-4, Treatment failure-5, Re-treatment Others-3 J Smear negative-18, Extra pulmonary-7
Hospital based study and comparatively smaller sample size are the limitations of the study. This is mainly due to the fact that only those cases who reside nearby and are willing to take the treatment in this DOTS center attached to the medical college hospital were included in the study. In spite of these, the study gives valuable information to the health care providers on the improvement of treatment related indicators because of constant follow-up of cases by the treating doctors. There is also a need to prioritize the issues for treatment of category 2 patients. To conclude, RNTCP is running successfully in this rural center as a public private partnership strategy with very low treatment failure rate, highlighting the importance of the same for the better treatment and control of tuberculosis. Table-2: Sputum conversion rates among study subjects

\begin{tabular}{|l|c|c|}
\hline Type of Patient & $\begin{array}{c}\text { At } 2 \text { months; } \\
\text { No. (\%) }\end{array}$ & $\begin{array}{c}\text { At 3 months } \\
\text { No. (\%) }\end{array}$ \\
\hline $\begin{array}{l}\text { New smear positive } \\
\text { ( } \mathrm{N}=14)\end{array}$ & $12(85.71 \%)$ & $13(92.86 \%)$ \\
Re-treatment & & \\
(Smear positive cases) & & \\
Relapse (N=4) & $3(75 \%)$ & $4(100 \%)$ \\
Failure $(\mathrm{N}=5)$ & $2(40 \%)$ & $4(80 \%)$ \\
\hline Total $(\mathrm{N}=23)$ & $17(73.91 \%)$ & $21(91.30 \%)$ \\
\hline
\end{tabular}

References:

1. World Health Organization. Global TB report 2010.

2. TB India 2006. RNTCP Status Report, Central TB Division, DGHS. Ministry of Health and Family Welfare; 200., pp. 8 and 52-53.

3. Managing the RNTCP in your area, Central TB Division, DGHS. Ministry of Health and Family Welfare; 2005; 1-4.

4. TB India 2011. RNTCP Status Report, Central TB Division, DGHS, Ministry of Health and Family Welfare, 2011; 114 - 15.

5. Bhat S, Sarin R, Jaiswal A, Chaudhary A, Singla N, Mukherjee S. Revised National Tuberculosis Control Programme: An urban experience. Indian J Tuberc 1998; 45:207-10.

6. Dholakia Y, Danani U, Desai C. Relapse following Directly Observed Therapy Short Course (DOTS) - A follow up study. Indian J Tuberc 2000; 47:233-36.

7. Pandit S, Dey A, Chaudhuri AD, Saha M,Sengupta A, Kundu S et al. Fiveyears experiences of the Revised National Tuberculosis Control Programme in northern part of Kolkata, India. Lung India 2009; 26:109-13.

8. Ganesh Kumar S, Harsha Kumar HN, Ramakrishna R, Jayarama S, Kotian MS. Trend of Tuberculosis Cases under DOTS Strategy in Dakshina Kannada District Of Karnataka, India: Issues and Challenges. Iranian J Publ Health 2009; 38:72-6.

9. Srivastva SK, Ratan RK, Srivastava P, Parsad R. Report on Revised National Tuberculosis Control Progamme- urban pilot project in Lucknow. Indian J Tuberc 2000; 47:159-61.

10. Chadha SL, Bhagi RP. Treatment outcome in tuberculosis patients placed under directly observed treatment short course (DOTS), a cohort study. Indian J Tuberc 2000;47:155-8. 